\title{
HEAT STRESS ON THE SPARK PLUG
}

\begin{abstract}
A. Dittrich ${ }^{*}$, S. Beroun ${ }^{* *}$
Abstract: The spark plug with integrated chamber increases the quality of ignition of the homogeneous mixture in the engine cylinder. The discharge of a very small amount of a burning mixture from the chamber (the so-called chamber ignition) leads to a faster development of the initial burning phase, and the subsequent burning of the mixture in the cylinder is then more stable in terms of inter-cycle variability. However, the spark plug housing with the integrated chamber is exposed to a higher thermal load compared to a conventional spark plug, and this must therefore be respected when constructing a spark plug with an integrated chamber. The paper shows the impact of the design of the spark plug with the integrated chamber on the temperature at the bottom of the cellular spark plug housing.
\end{abstract}

Keywords: spark plug, integrated chamber, thermal stress, temperature field

\section{Introduction}

The decisive influence on the parameters of the working cycle and on the operational characteristics of the internal combustion engine is the burning behavior of the mixture in the engine cylinder. Besides the physical quantities describes the burning process (start of burning, burning rate, total burning time, temperatures and pressures in the cylinder), the stability of the process of the combustion process (repeatability, reproducibility of the above-mentioned physical quantities) in the working cycles engine. Despite the apparent uniqueness condition for the beginning and the subsequent process of burning (prepared homogeneous mixture is ignited high-voltage discharge at the electrodes of the spark plug (SP)) with gasoline engines to engines diesel substantial variations waveform burn-mixture in the cylinder, which is reflected variations in cylinder pressure between the working cycles of the engine. The reasons for the variability are given by a small initiation energy to create a burning focus in a spark ignition engine (spot ignition with energy of about $10-40 \mathrm{~mJ}$ in a small volume of the mixture around the spark plug electrodes: with a diesel engine, the ignition initiation is initiated by about 3 orders of magnitude higher, ignition point over the entire volume of the combustion chamber).

At TU in Liberec, there is conducted an experimental study of ignition of the prepared homogeneous mixture by an integrated chamber spark plug (SPWIC), filled during compression with a certain amount of fresh mixture from the engine cylinder. High-voltage discharge is ignited both in the combustion chamber of the engine cylinder and in the chamber. The very rapid burning of the mixture in the protected volume of the chamber without the negative influence of the turbulence on the development of the burning. This leads to the discharge of the burning mixture into the main combustion chamber and thus, in many places, ignites the mixture in the main combustion chamber. Almost simultaneous mix sparking in multiple locations, coupled with turbulence, promotes the development of a fast and relatively stable process in the main combustion chamber.

Due to the occasional damage to the central electrode (see Figure 1) at a higher engine load caused probably by SPWIC being more exposed to heat and the temperature at the end of the central electrode may be higher than in the conventional SP, temperature measurements were made on both conventional SP, and SPWIC. Subsequently, 3D models of the SPWIC variants were created and the thermal stress was

\footnotetext{
* Ing. Aleš Dittrich: Technical University of Liberec, Studentská 2; 461 17, Liberec 1; CZ, ales.dittrich@tul.cz

** Prof. Ing. Stanislav Beroun, CSc.: Technical University of Liberec, Studentská 2; 461 17, Liberec 1; CZ, stanislav.beroun@tul.cz
} 
also verified by calculation. The results of the temperature measurements were then used to verify the correctness of the thermal stress models of both conventional SP and spark plugs with integrated chamber.

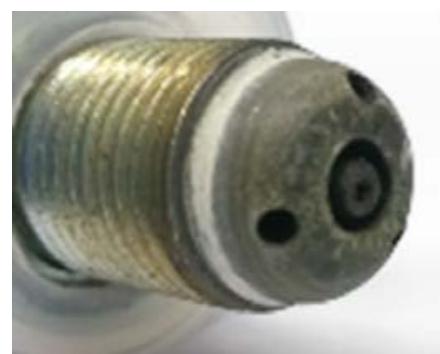

Fig. 1: View of the damaged SPWIC central electrode.

\section{Temperature measurement in spark plug housing}

To determine the real thermal stress of the lower part of the spark plug, the sleeves (both - classic SP and SPWIC) were modified in cooperation with BRISK a.s. and SMALL HOLE DRILLING Ltd. In the case of a SP, two holes $\mathrm{D}=0.46 \mathrm{~mm}$ were placed so that they were $0.5 \mathrm{~mm}$ from the base of the spark plug case (total micron $22.4 \mathrm{~mm}$ ). The holes are mutually shifted by $180^{\circ}$ around a vertical axis. One hole was thus located in the outer shell of the spark plug housing and the other was located according to the external spark plug's electrode. These two holes connect holes of diameter $\mathrm{D}=1.1 \mathrm{~mm}$ diverted at an angle of $18^{\circ}$ from the vertical axis of the spark plug housing inside the candle housing.

After the spark plug was assembled into a functional unit, the guiding tubes for the sheathed thermocouple (type J - diameter $0.25 \mathrm{~mm}$ marked "sp - electrode" and "sp - bottom" see Figure 2) were then inserted (and fixed).

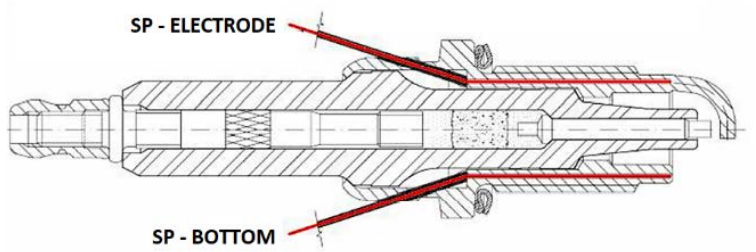

Fig. 2: Location and labeling of thermocouples in spark plug.

Figure 3 shows the case of the measuring SPWIC. On the periphery of the housing, similar to the SP measuring case, two holes $\mathrm{D}=0.46 \mathrm{~mm}$ are drilled to place the thermocouples up to the bottom of the SPWIC. One again positioned $0.5 \mathrm{~mm}$ from the bottom edge of the bottom of the plug (between holes), the other was placed in the plug housing above the hole.

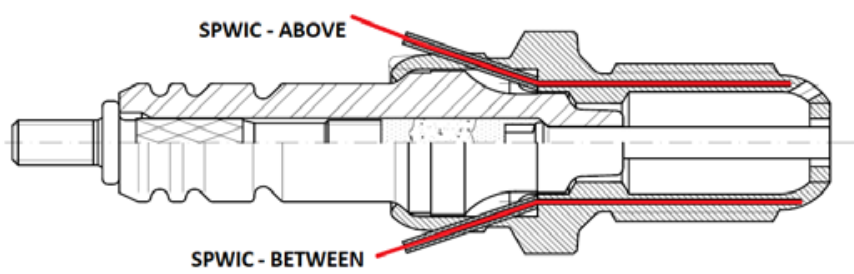

Fig. 3: Location and marking of thermocouples in spark plug with integrated chamber.

The program of measurement on modified classical spark plugs adapted for temperature measurements took place within the range of the external revolutions characteristic and several load characteristics. Measurement program with modified spark plugs with integrated chamber was carried out for technical reasons (short-circuit to central electrode - after that engine was operated in so-called safe mode during the engine load characteristics at $5000 \mathrm{rpm}$ ) only for engine load characteristics. Part of the results are processed and graphically compared in the graphs in Figure 4. 

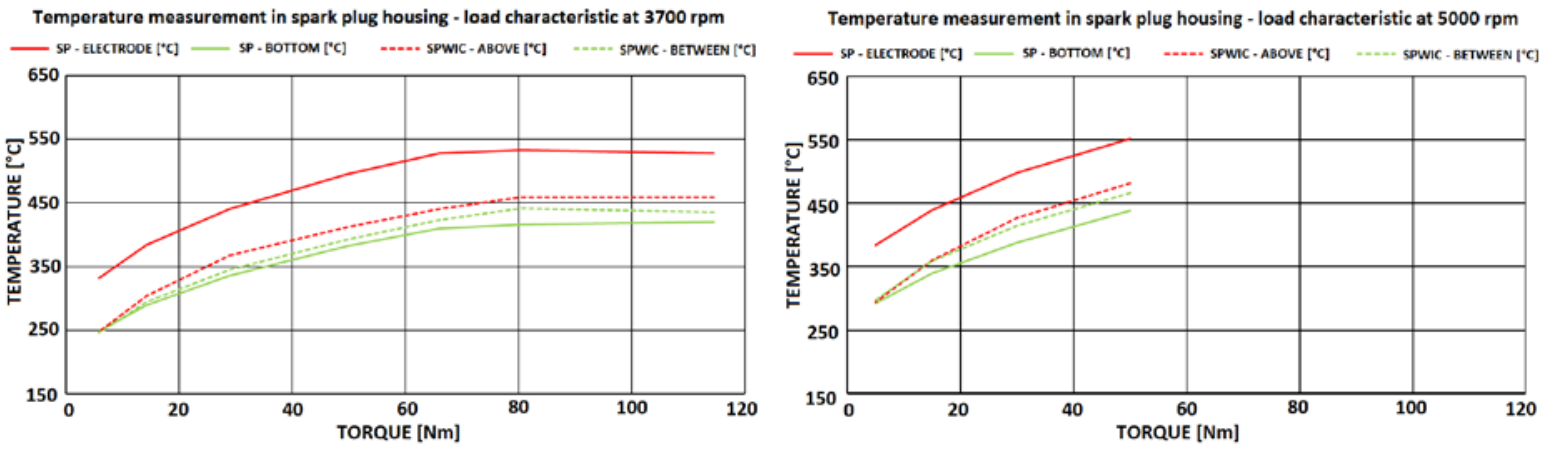

Fig. 4: The measured temperatures of the spark plugs at engine load characteristics for 3700 rpm (on the left side) and $5000 \mathrm{rpm}$ (on the right side).

\subsection{Temperature field modeling}

The CREO Parametric 2.0 software and its superstructure to calculate thermal stress using the finite element method - Creo Simulate, were used to model the temperature field. The calculation model is considered as a half model with a cut in the axis of the spark plug. Then the boundary conditions were applied to the calculation model. For intake, exhaust and engine cooling channels were used boundary condition called Convection condition where the heat transfer is determined by the temperature (taken from real data measurement) and value of the heat transfer coefficient (according to Mikulanin (2014)). The boundary condition Heat load was used for the area of the combustion chamber and the individual components of the spark plug, where the calculated (from real data measurement on the same internal combustion engine) heat flux density value is entered $-0.62 \mathrm{~W} \cdot \mathrm{mm}^{-2}$ for $3700 \mathrm{rpm}$ and $1,01 \mathrm{~W} \cdot \mathrm{mm}^{-2}$ for $5000 \mathrm{rpm}$. The computational model was compared with the measured temperatures for the classic and chamber spark plugs.

Computational models were made for 3 cases of SPWIC with an internal volume of $1 \mathrm{~cm}^{3}$ and for a classic spark plug. Due to the above-mentioned problem with the occasional damage of the central electrode one computational model of SPWIC has a shortened central electrode and then extended by a tungsten (material with high thermal conductivity) rod (diameter $\mathrm{D}=1.6 \mathrm{~mm}$, which will be fixed to the central electrode by the high-temperature vacuum technology soldering).

\section{Boundary conditions}

The components of the individual spark plugs were created either according to the drawing documentation (in the case of the classical SP from Brisk), or the SPWIC models used to create the drawing documentation. The cylinder head model was used on the basis of the data received from the Škoda auto - a model corresponding to the cylinder head of the engine on the braking station was used, i.e. the EA111.03E 4-valve engine head. The way of marking each of the main places for entering boundary conditions is shown in the Figure 5.

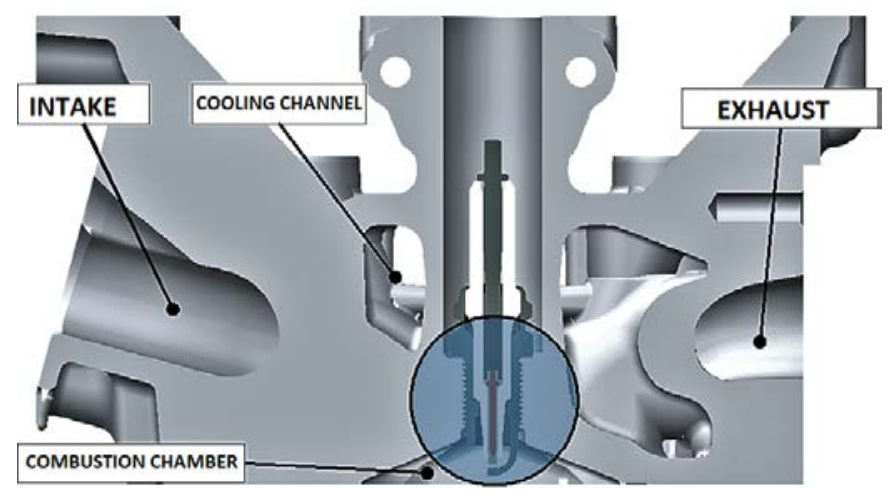

Fig. 5: The way of marking each of the main places for entering boundary conditions - cylinder head.

Based on the measured temperatures in the spark plug case (both - classical and SPWIC) and according to previous experience on Department of Vehicles and Engines at Technical university of Liberec and 
According to Mikulanin (2014) a simplified calculation for two speed modes (3700 and 5000 rpm - full load) was made. The measured temperatures at $3700 \mathrm{rpm}$ on the spark plugs were introduced into calculation. Differences between calculation and measurement was not higher than $5 \%$, then the model was prepared for 5000 rpm case (see Fig. 6).
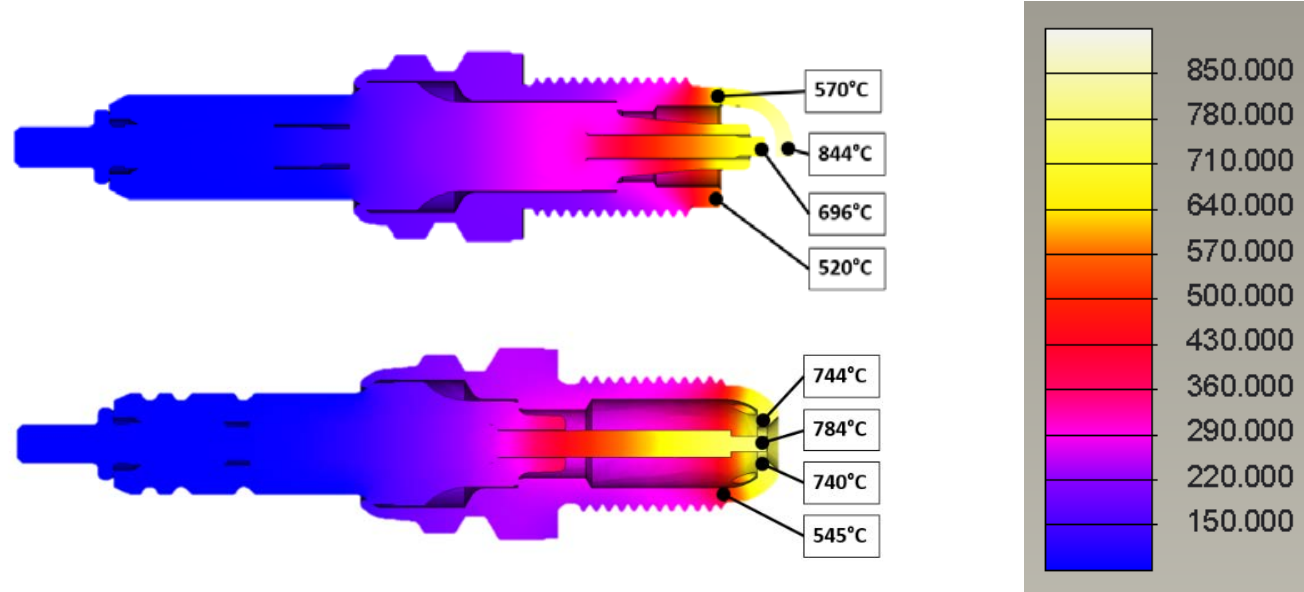

Fig. 6: Top: Temperature analysis of the classic spark plug model at 5000 rpm.

Bottom: Temperature analysis of the SPWIC - central electrode with tungsten "rod" at 5000 rpm.

\section{Conclusions}

The results of the simulation model of the temperature fields for the individual variants of the spark plugs show the influence of the total number and position of the holes on the total thermal stress of the lower part of the SPWIC, as well as the influence of the length of the central electrode on the maximum reached temperature. The results from temperature simulation of the classic SP and SPWIC models coincide quite well with the results from the temperature measurements at the same points (real temperature should be bit higher - it's caused by bad touch of thermocouple to the body of the spark plug). In the case of the future variant of SPWIC with an extended tungsten rod electrode, the maximum temperature on the central electrode was higher compared to the same model without tungsten "rods" by about $50{ }^{\circ} \mathrm{C}$ at 3700 rpm. On the other hand, at the speed of $5000 \mathrm{rpm}$, the maximum temperature at the tip of the central electrode was reduced by about $90{ }^{\circ} \mathrm{C}$ according to the model of the temperature field.

\section{Acknowledgement}

The results of this project LO1201 were obtained through the financial support of the Ministry of Education, Youth and Sports in the framework of the targeted support of the "National Programme for Sustainability I" and the OPR\&DI project Centre for Nanomaterials, Advanced Technologies and Innovation CZ.1.05/2.1.00/01.0005.

\section{References}

Blažek, J. a Stanislav Beroun. Spark plug with the increased energy for creating of initial combustion centre. Journal of KONES Power train and Transport. Vol. 15, No.3/2008. Warsaw 2008, ISSN 1231-4005.

Beroun, S., Dvořák, V., Blažek, J. Chamber-type ignition for an SI engine. Journal of Middle European Construction and Design of Cars MECCA, vol. VIII, no. 2/1010, ISSN 1214-0821.

Beroun, S., Pavel Brabec, Aleš Dittrich a Lukáš Mikulanin. Temperature field of spark plug in the SI engine. Engineering Mechanics 2014, Brno University of Technology, Brno, 2014, pp 84-87. ISSN 1805-8248.

Beroun, Stanislav, Pavel Brabec, Aleš Dittrich a Lukáš Mikulanin. Optimalisation of Spark Plug with integrated Chamber. XLV. International Scientific Conference of the Czech and Slovak University Departments and Institutions Dealing with the Research of Internal Combustion Engines. ISBN 978-80-7375-801-1

Mikulanin, Lukáš. Zapalovací svíčka s integrovanou komůrkou: Spark Plug With Integrated Combustion Chamber [CD-ROM]. Liberec: Technická univerzita v Liberci, 2014. 